\title{
Diversity of fruit fly species (Diptera: Tephritidae) associated with citrus crops (Rutaceae) in southern Benin in 2008-2009
}

\author{
Jean-François VAYSSIERES ${ }^{1 *}$, Appolinaire ADANDONON ${ }^{1}$, Antonio SINZOGAN ${ }^{1}$ \\ and Sam KORIE ${ }^{2}$ \\ ${ }^{l}$ CIRAD-Persyst, UPR Production Fruitière, IITA, 08 BP 0932, Cotonou, Benin. Tél. (229) 21.35.01.88 \\ ${ }^{2}$ IITA-Ibadan, IITA Ltd., Carolyn House, 26 Dingwall Road, Croydon CR9 3EE, UK \\ *Corresponding author, E-mail: j.vayssieres@cgiar.org
}

\begin{abstract}
Fruit flies are pests of economic importance in many fruit crops. Little was known about Tephritid diversity in citrus orchards in southern Benin prior to this study. Traps baited with parapheromones were set in citrus orchards from August 2008 to August 2009 in the Atlantique, Ouémé and Zou departments to identify fruit fly species and monitor the fluctuation of their populations. Citrus fruits were also sampled during the citrus season (from August 2008 through August 2009) at two-week intervals and assessed in the laboratory for fruit fly damage. Other cultivated and wild fruits near the citrus orchards were also collected. The fruit fly detection trapping showed that Bactrocera invadens Drew Tsuruta \& White followed by Dacus bivittatus (Bigot), was the most predominant species recorded in Citrus orchards. Bactrocera cucurbitae (Coquillett) was also recorded along with six species of Ceratitis. From all fruits sampled, the emerged fruit fly species were primarily B. invadens (98.3\%), followed by B. cucurbitae, Ceratitis fasciventris (Bezzi), Ceratitis ditissima (Munro), Ceratitis anonae Graham and Dacus punctatifrons Karsch. The infestation rate was highest on Citrus reticulata Blanco (22\%), followed by C. tangelo Macfad (18.7-19.7\%) and Citrus sinensis Osbeck (5.3$8.74 \%$ ). These results are significant for the decision-making process for effective monitoring and management of $B$. invadens in citrus orchards in southern Benin.

(C) 2010 International Formulae Group. All rights reserved.
\end{abstract}

Keywords: Citrus spp., Bactrocera invadens, Bactrocera cucurbitae, Ceratitis spp., Dacus spp., southern Benin.

\section{INTRODUCTION}

Fruit flies (Diptera: Tephritidae) are pests of economic importance in many crops including mango, Mangifera indica L. (Anacardiaceae), Citrus spp. (Rutaceae), guava, Psidium guajava L. (Myrtaceae) and many other fruits (White and Elson-Harris, 1992; Alemany et al., 2006; Da Silva et al., 2006; Llod et al., 2010). In tropical regions, fruit flies can wreak great economic devastation on crops such as mangoes and citrus species (Thompson, 1998; Lux et al., 2003; Umeh et al., 2008). For instance, in northern and central Benin, the recorded damage on mangoes ranged from $17 \%$ in early April to $73 \%$ in mid-June for seasons 20052006 (Vayssières et al., 2009a). About a dozen species of Tephritidae, four of which are economically important, have been identified as colonizing mango trees in central 
and northern Benin (Vayssières et al., 2005), resulting in a huge loss of economic opportunity for the incomes of the cultivating populations involved.

Knowledge on species diversity of mango fruit flies in Benin and the associated crop and income losses was previously limited. Mango production is carried out in northern and central Benin, but the largest citrus plantations are in the southern departments of Atlantique, Ouémé and Zou where knowledge on tephritid diversity in citrus orchards was poor before this study. The main citrus species encountered in these departments during the study were (i) Citrus sinensis Osbeck (sweet orange): cv. Valencia, Pineapple, Navel, local; (ii) Citrus reticulata Blanco (mandarin): cv. Dancy, Fairchild, local; (iii) Citrus aurantifolia (lime); (iv) Citrus reticulata Blanco $\times$ Citrus paradisi Macfad or C. tangelo (tangelo): cv. Orlando; (v) Citrus sinensis Osbeck $\times$ Citrus reticulata Blanco (Tangor): cv. Ortanique; and (vi) Citrus paradisi Macfad (Pomelo): cv. Shambar, Marsh. According to most citrus growers in southern Benin, infestation and losses due to frugivorous insects were high, showing the importance of studying both the spatial and temporal agro-ecological variability of these frugivorous pests in the Guineo-Congolian zone of Benin.

In neighbouring Nigeria, the association of fruit flies with citrus crops has been detailed with species diversity, relative abundance and spread in major producing areas (Umeh et al., 2008). The main species were Bactrocera invadens Drew Tsuruta \& White, Bactrocera cucurbitae (Coquillett), Ceratitis ditissima (Munro), Ceratitis capitata (Wiedemann) and Dacus bivittatus (Bigot). However, in 2000-2001 only C. capitata was recorded as a fruit fly pest in Nigeria (Umeh et al., 2004). In Ghana, only the medfly, $C$. capitata, was highlighted as a major fly pest in 2006 in citrus crops (Fappiah et al., 2009), while $B$. invadens was not mentioned by these authors for season 2006 in Ghana's Eastern region. Mwatawala et al. (2009) recorded $B$. invadens, C. capitata, Ceratitis rosa Karsch and very few $C$. capitata on Citrus hosts in Tanzania in East Africa. The Mediterranean fruit fly ( $C$. capitata) and the Natal fly (Ceratitis rosa Karsch) are important pests of citrus fruits in both southern Africa (Du Toit, 1998; Grout and Stoltz, 2007) and on Reunion island (Vincenot and Quilici, 1993; Quilici and Thuy Nguyen, 2004). In Asia, Bactrocera dorsalis (Hendel) remains the main Citrus fly pest in China (Yang et al., 2009) and also in India with Bactrocera zonata Saunders (Sanjeev et al., 2008).

The substantial revenue losses due to fruit flies make it a matter of urgency to identify appropriate control methods for protecting fruit plantations against the fruit fly pressure. For a fly pest control strategy to be effective, factors such as fly population, its fluctuations, its spatial and temporal distributions, its host range are important aspects for forecasting spread of fruit flies. This is a prerequisite for any control measures targeting the fruit fly species of economic importance. In this regard, fruit fly detection by trapping is a practical method that helps track fluctuations in the pest population, thereby providing information to help integrate methods of minimum pesticide and biological control into IPM packages for ecologically sustainable control of the fly targets.

Although a lot of research work is being conducted in the northern part of Benin on fruit fly incidence on mango, damage and control strategies, little is known for southern Benin about the fruit fly species present, their spatial and temporal fluctuation and the damage caused to citrus production. The objective of the present work was to conduct a fruit fly detection-trapping trial in citrus orchards in southern Benin to identify the different fly species and study fruit fly population fluctuation so that data could be correlated with damage caused to fruit by the flies. 


\section{MATERIALS AND METHODS Choice of trial sites}

The choice of sampling sites was based on the following criteria: (i) a minimum area of 3 ha, (ii) trees regularly spaced, (iii) the farmer's agreement not to apply any chemical treatments within the orchard or even in the immediate vicinity, and (iv) identification of species and cultivars of citrus crops. Four orchards on four different sites were selected within a radius of about $100 \mathrm{~km}$ around Cotonou. The characteristics of these citrus orchards are shown in Table 1. The four selected sites in this Guineo-Congolian agroecological zone were on a north-south axis with sites north of Cotonou at (i) Glo, (ii) Govié (Allada 1) and (iii) Lokodénou (Allada 2), with (iv) Sakété (East Cotonou). The site temperatures $\left({ }^{\circ} \mathrm{C}\right)$ and relative humidity (\%) were recorded using Tinytag data loggers (Gemini Data Loggers UK Ltd). Data was then automatically recorded every $10 \mathrm{~min}$ by each Tinytag for later computer analysis.

\section{Diversity and seasonal fluctuations of Tephritidae in citrus orchards}

At the beginning of August 2008, a total of 44 traps were installed in the selected orchards. The traps were hung from a primary branch of the lower third of the leaf canopy, at a medium distance from the centre of the tree. The traps were set in such a way that they were not directly exposed to sunlight, but permitted easy access. The wire suspending each trap was coated with solid grease in order to prevent any predatory activity by ants (Oecophylla) on the dead Tephritidae adults caught in the trap. Counts were made every week.

At each selected site, dry traps containing sex attractants (parapheromones), namely terpinyl acetate, trimedlure, methyl eugenol and cuelure were used to attract predominantly male fruit flies. Of the four citrus orchards, three had three attractants of each type while the fourth orchard had only two attractants of each type, resulting in 11 terpinyl acetate, 11 trimedlure, 11 methyl eugenol and 11 cuelure traps, totalling 44 for the four orchards. The parapheromone traps were set at a distance of at least $40 \mathrm{~m}$ to each other for differently-baited traps, to prevent any interaction between attractants. For each trap type, there were three repetitions per site. Attractants and DDVP (dichlorvos) insecticides were changed every month for greatest efficacy. The traps were visited every week to count the number of caught flies per trap, enabling the fruit fly population to be monitored and the different fly species also identified per site and per week. To evaluate the similarity of populations of fruit fly species among the sites or orchards, various similarity coefficients were calculated, including species richness, Shannon index (H'), Shannon evenness $\left(\mathrm{E}_{\mathrm{H}^{\prime}}\right)$, and Simpson diversity (Oates et al., 2005; Dalirsefat et al., 2009). The choice of an appropriate coefficient of similarity is a very important and decisive point for evaluating similarity between individuals, analyzing diversity within populations and studying relationship between populations, because different similarity coefficients may yield conflicting results (Kosman and Leonard, 2005).

\section{Tephritidae associated with citrus crops}

Citrus fruit samples were taken from the selected four sites from August 2008 through August 2009. Fruits were sampled from four citrus species, depending on fruit availability. In Glo-djigbé, these were sweet orange $(C$. sinensis) $\mathrm{cv}$. Valencia and $\mathrm{cv}$. Pineapple, mandarin (C. reticulata) cv. Dancy, tangelo $(C$. reticulata $\times C$. paradisi $)$ cv. Orlando, and tangor $(C$. sinensis $\times C$. reticulata) cv. Ortanique. Two types of fruit were available in Sakété $(C$. sinensis cv. Valencia and $C$. reticulata), one type in Govié, Allada (C. sinensis cv. Valencia) and one species with two cultivars in Lokodénou, Allada (C. sinensis, cv. Valencia and cv. Pineapple). Thirty fruits were picked at random at two-week intervals from 10 antfree trees per site and per cultivar. There were $1680,660,570,480$ and 330 fruits of $C$. 
sinensis (Valencia), C. reticulata (Dancy), $C$. sinensis (Pineapple), $C$. reticulata $\times C$. paradisi (Orlando) and $C$. sinensis $\times C$. reticulata (Ortanique), respectively, giving 3 720 fruits in total for the year's sampling. Neither pomelo ( $C$. paradisi) nor limes $(C$. aurantifolia) were collected because they were regularly treated with insecticides.

Fruit samples were individually weighed, counted and classified in the laboratory by variety, date and sample site. After being allocated a sequence number, they were placed for observation onto mesh supports mounted on basins filled with wet sand into which larvae emerging from the fruits could drop and metamorphose into pupae (Vayssières et al., 2007). For each variety, the batches were individualised according to the site and their sampling date for easy referencing of the sample origin. At five-day intervals, the sand covering the bottom of the containers was sieved to collect the pupae with flexible tweezers. They were then given a sequence number and placed in small hatchery boxes that were checked every three days to collect the adults for identification using a binocular magnifier.

\section{Tephritidae associated with other fruit crops}

Fruits from wild fruit crops around selected citrus orchards were also sampled during the appropriate fruiting periods to identify fruit fly linked to those crops. Thirty fruits were sampled at two-week intervals from Terminalia catapa L. in Sakété, and from Carica papaya L., Annona muricata L., Psidium guajava L., Mangifera indica L., Chrysophyllum albidum G. Don, Irvingia gabonensis (Aubry-Lecomte) in Ouidah and Allada.

\section{Statistical analysis}

Infestation rate was calculated as the number of larvae/kg fruit. $\log 10 \quad(\mathrm{x}+1)$ transformation was used on percentage data to stabilize the variance and normalize the data. Analysis of variance was performed using the general linear model procedure, and mean separations were done using the Student Newman Keuls test under SAS (2003).

\section{RESULTS}

Captures and seasonal fluctuations of Tephritidae populations in citrus orchards

For each fruit fly species, the captures of trapped flies were added up during the 52 consecutive weeks of trapping (Table 2). The 44 traps set up in citrus orchards captured a total of 92989 Tephritid adults (Table 2) distributed in six species of Ceratitis, two of Bactrocera and four of Dacus (Table 2). These were $C$. cosyra, $C$. ditissima, $C$. fasciventris, C. anonae, C. capitata, C. bremii, B. invadens, B. cucurbitae, D. bivittatus, D. punctatifrons, Dacus langi Curran and Dacus pleuralis Collart. All species, except $C$. anonae, were found at all sites.

For the four sites, B. invadens was the most predominant fly species, totaling 82507 individuals and representing $88.73 \%$ of the total captures. It was far in excess of the next most numerous fly species, $D$. bivittatus with 5924 examples, representing just $6.37 \%$ of the total. In general, the population of Ceratitis spp. at each of the four sites was very low, totaling 1499 individuals, representing only $1.6 \%$ of all fruit flies recorded.

Of the six species of Ceratitis, $C$. capitata was the most abundant, representing more than half the total Ceratitis population recorded at the four sites. $C$. ditissima and $C$. fasciventris were in second and third positions after $C$. capitata (Table 2). Other Ceratitis species were $C$. cosyra, $C$. bremii and $C$. anonae. The latter was not recorded in Sakété.

B. cucurbitae represented only $0.38 \%$ of the total amount of Tephritids recorded, and most of these were recorded at Sakété, with about $65 \%$ of all B. cucurbitae recorded on the four sites. The weekly population fluctuations of the fruit flies in the citrus orchards per trap during the 52 consecutive weeks are shown in Figures 1-4. 
At all four sites, $100-300$ of $B$. invadens were recorded per trap per week at the end of August/beginning September 2008, and this consistently decreased thereafter to less than 50 flies per trap per week in December 2008. The population hovered around this low value through April 2009. From that point on, the population began increasing to reach a peak of more than 600 flies per trap per week in June, except in GloDjigbé, Abomey-Calavi where it peaked at around 400. The highest population of $D$. bivittatus was mostly recorded in November.

The one-year total sum of recorded species showed that there were 12 fruit fly species per site, except in Sakété with 11 fruit fly species. However, the weekly mean of fruit fly species richness was the highest in Allada while the lowest was recorded in Sakété, although the difference was not significant $(P=0.05)$ (Table 3$)$. Moreover, the mean values of Shannon diversity, Simpson diversity, and Shannon evenness were also not significantly $(P=0.05)$ different among sites. The Shannon evenness or equitability values obtained in the current study were low (less than 0.4) indicating that the weekly species equitability is low, which is obvious since at all the studied sites, $B$. invadens alone accounted for more than $88 \%$ of the total number of recorded species (Table 2).

Temperature and relative humidity recorded during the study are shown in Figures 1-4. The mean temperature varied around $30^{\circ} \mathrm{C}$. The relative humidity trend was similar to that of the fruit fly population fluctuation, showing movement mainly from April to mid-June 2009. This trend was recorded at all studied orchard /sites. After peaking around 4-10 June 2009, both curves (of humidity and fruit fly fluctuation) decreased until around 18-25 June 2009. Fruit fly populations, especially $B$. invadens, were peaking in May and June, coinciding with important rains and first fruiting - maturity of citrus fruits (Figures 1-4).

In our study, we have obtained at least $98 \%$ of $B$. invadens infestation in citrus fruits
(Table 4). B. invadens is really abundant during first citrus fruiting period from May to August (Table 1). B. invadens incidence as high as $35 \%$ was recorded on $C$. reticulata (Table 4) with 22 pupae per $\mathrm{kg}$ of fruit and $27 \%$ on C. tangelo (Table 4) with 19 pupae per $\mathrm{kg}$ of fruit.

From papaya samples, both $D$. bivittatus and $B$. invadens were recorded (Table 5) and some moths, Thaumatotibia leucotreta Meyrick (Lepidoptera: Tortricidae), were also but very seldom recorded emerging from some sweet oranges.

\section{Lure responses \\ Trimedlure}

Trimedlure in this experiment attracted males of $C$. fasciventris, $C$. capitata and $C$. anonae. Trimedlure remains the best attractant for this species.

\section{Terpinyl acetate}

Terpinyl acetate is the attractant capturing males of $C$. cosyra. It is the only attractant capturing many individuals of the marula fly, C. cosyra.

\section{Methyl eugenol}

Methyl eugenol is very effective for $B$. invadens and also rare species of Ceratitis. It was able to capture males of $C$. bremii and, very seldom, males of $C$. fasciventris.

\section{Cuelure}

During the current trapping, it mostly captured males of $D$. bivittatus, $D$. punctatifrons, D. langi, D. pleuralis and also B. cucurbitae.

\section{Incidence and infestation rates of Tephritidae in citrus fruits}

From all fruits sampled, emerged fruit fly species were mostly B. invadens $(98.3 \%)$ and secondarily B. cucurbitae, C. fasciventris, $C$. ditissima, $C$. anonae, D. bivittatus and $D$. punctatifrons (Table 4). Ceratitis species only represented $1.1 \%$ of all Tephritid species emerging from incubated, sampled citrus fruits (Table 4).

The infestation rate - as number of pupae per $\mathrm{kg}$ fruit - was highest in 
significance $(P<0.05)$, on $C$. reticulata (22.5\%) at Sakété (East Cotonou), followed by C. tangelo ( $18.7 \%$ and up to $19.7 \%$ in November) and C. sinensis (cv. Valencia) (5.3\% and up to $8.74 \%$ in November). $C$. sinensis $\times C$. reticulata and $C$. sinensis (cv. Pineapple) were less infested (Table 4). Some of the pupae recorded from infested fruits did not hatch and these unhatched pupae were in a proportion of $3.2,3.3,3,6$ and $4.2 \%$, respectively, for $C$. sinensis cv. Valencia, $C$. sinensis cv. Pineapple, $C$. reticulata and $C$. tangelo. Incidence recorded during the study as percentage of fruit fly-infected fruits is shown in Table 4. The incidence was of greatest significance $(P<0.05)$ on $C$. reticulata $(35.0 \pm 6.6)$, followed by $C$. tangelo $(27.1 \pm 10.1)$ and $C$. sinensis cv. Valencia (20.4 \pm 3.2$)$, while the lowest was recorded on $C$. sinensis cv. Pineapple and $C$. sinensis $\times$ C. reticulata $($ Table 4).

\section{Tephritidae associated with other cultivated and local hosts}

The main fruit fly species emerging from sampled fruits collected from all other cultivated and wild fruit species was $B$. invadens. The infestation rate per plant is shown in Table 5. We have to highlight that C. papaya is also a host for D. bivittatus, $P$. guajava for $C$. fasciventris, A. muricata for $C$. cosyra, C. albidum for $C$. ditissima and $C$. fasciventris. Another article will develop all these relations plant-insects.

\section{DISCUSSION}

Captures and seasonal fluctuations of Tephritidae populations in citrus orchards

Fruit flies species recorded in the current study included species of the genera Bactrocera, Ceratitis and Dacus. In total, over the full year cycle, 92289 specimens were collected with $B$. invadens as the predominant fly species with $88.7 \%$ of the total captures. All species, except $C$. anonae, were found at all sites, and, all species, except $D$. langi and
D. pleuralis, were previously reported in Benin. For the four sites, alpha diversity is thus represented by 12 tephritid species with four species poorly represented namely $C$. anonae, C. bremii, D. langi and D. pleuralis.

Beta diversity can measure how different or similar habitats or samples are in terms of the variety of species. According to our results, we can see that no significant difference was detected among the 4 sites and using both Shannon and Simpson indices. This is not surprising because we have studied quite the same four Citrus orchards in the same agro-ecological zone, with the same production system and also at the same altitude.

Fruit fly populations, especially $B$. invadens, were peaking in May and June, coinciding with important rains and first fruiting - maturity of citrus fruits. This might indicate that not only is relative humidity among factors influencing fruit fly populations, but also the fruiting maturity of the different Citrus species. These results are consistent with those found by Vayssières et al. (2009a). These authors showed that temperature, relative humidity, important rains and host plant stages are the main factors influencing fruit fly populations, mainly the Asian species, B. invadens. Vayssières et al. (2009a) demonstrated that an increase of populations of $B$. invadens at the beginning of the rainy seasons coincided with fructification of mango cultivars and resulted in great yield losses to late-season maturing cultivars. In our study, we have obtained at least $98 \%$ of $B$. invadens infestation in citrus fruits (Table 4). $B$. invadens is peaking during their fruiting period from May to August. These results have been found in citrus in the current study where $B$. invadens incidence as high as $35 \%$ was recorded on $C$. reticulata (Table 4) with 22 pupae per $\mathrm{kg}$ of fruit and $27 \%$ on $C$. tangelo (Table 4) with 19 pupae per $\mathrm{kg}$ of fruit. 
J. F. VAYSSIERES et al. / Int. J. Biol. Chem. Sci. 4(6): 1881-1897, 2010

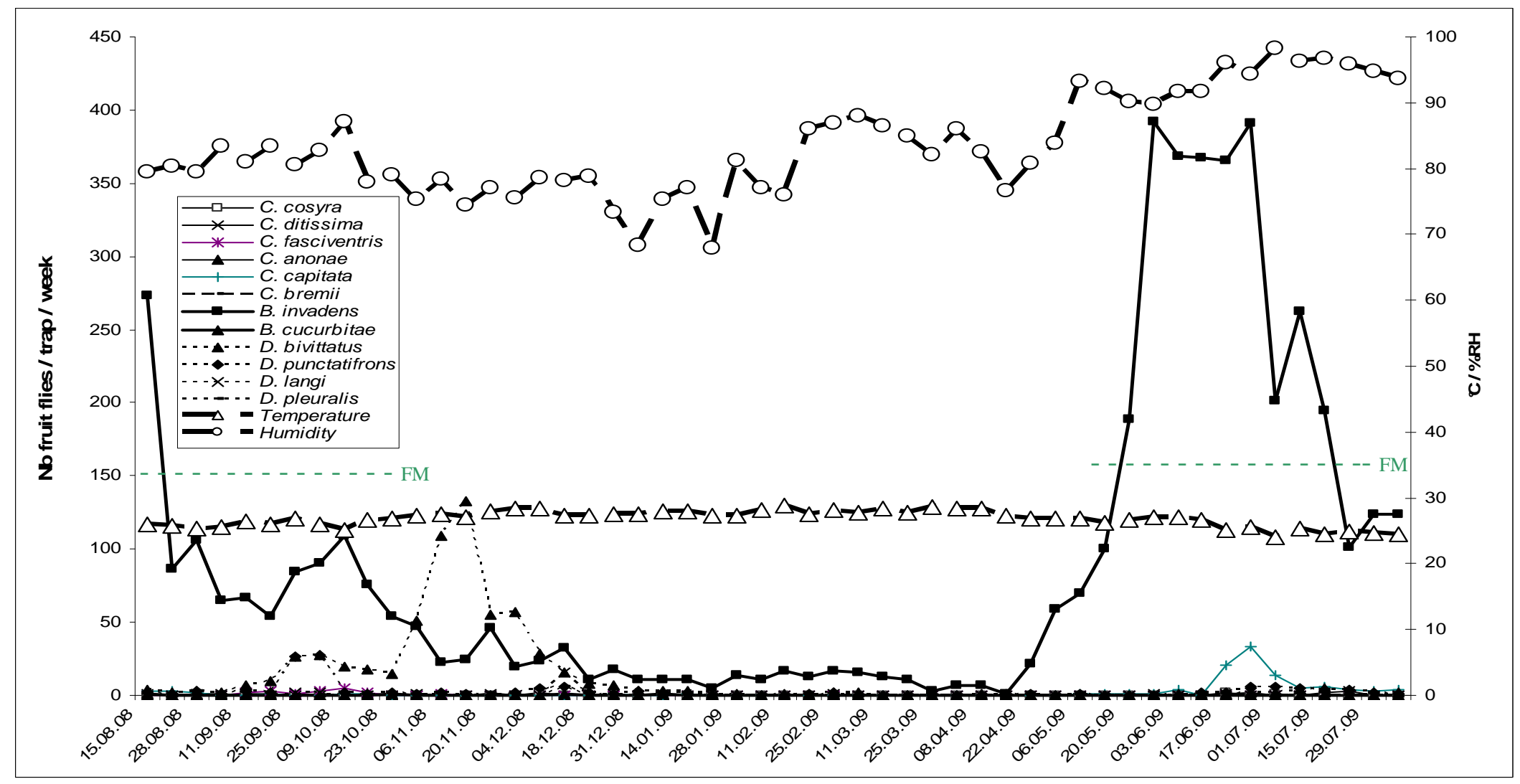

Figure 1: Amount of fruit flies (Ceratitis spp., Bactrocera spp., Dacus spp.) observed per trap per week in relationship with temperature / relative humidity recorded in a citrus orchard in Glo-Djigbé, Abomey-Calavi from August 2008 to August 2009. FM = fruiting maturity. 
J. F. VAYSSIERES et al. / Int. J. Biol. Chem. Sci. 4(6): 1881-1897, 2010

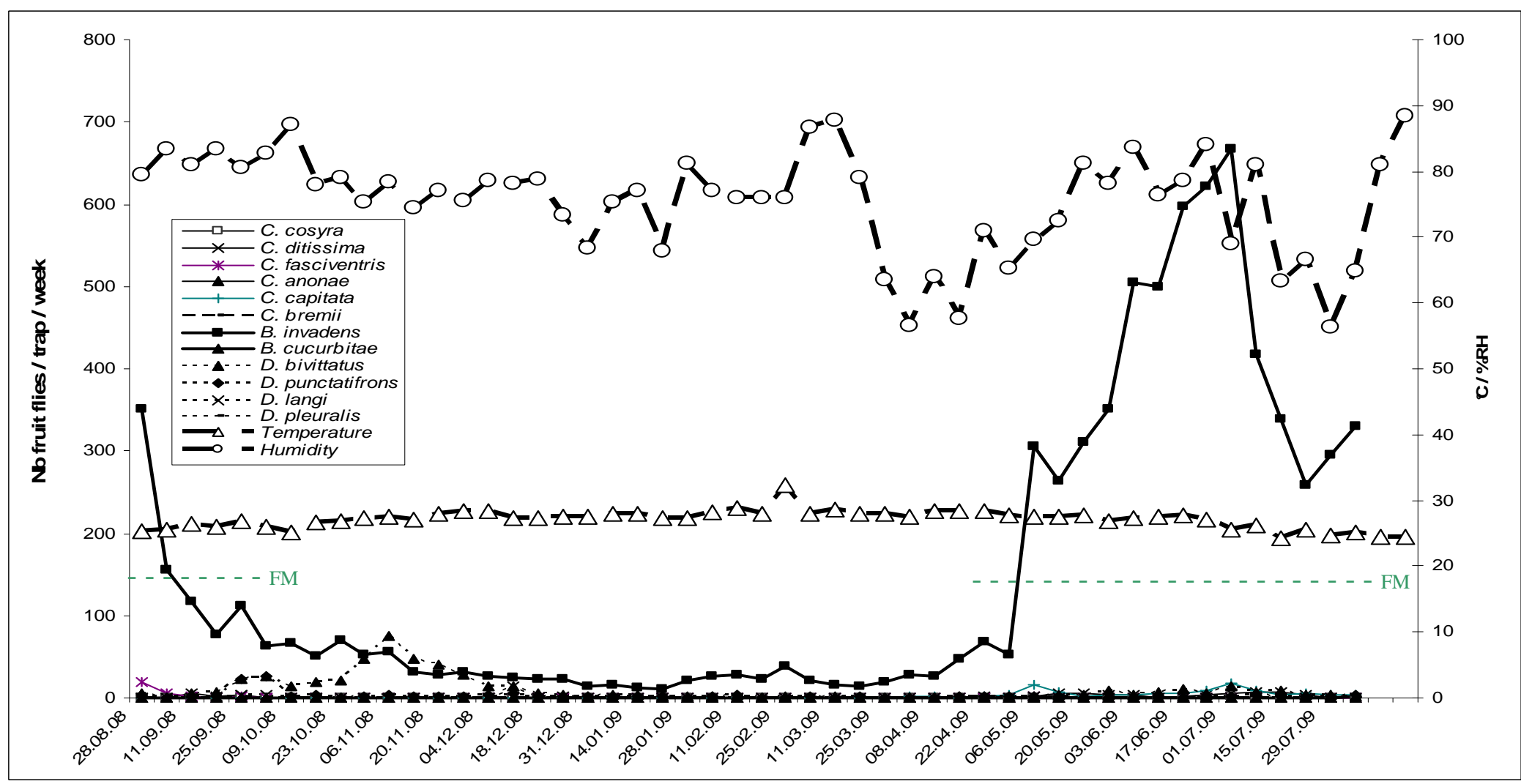

Figure 2: Amount of fruit flies (Ceratitis spp., Bactrocera spp., Dacus spp.) obtained per trap per week in relationship with temperature / relative humidity recorded in a citrus orchard in Govié, Allada from August 2008 to August 2009. FM = fruiting - maturity. 
J. F. VAYSSIERES et al. / Int. J. Biol. Chem. Sci. 4(6): 1881-1897, 2010

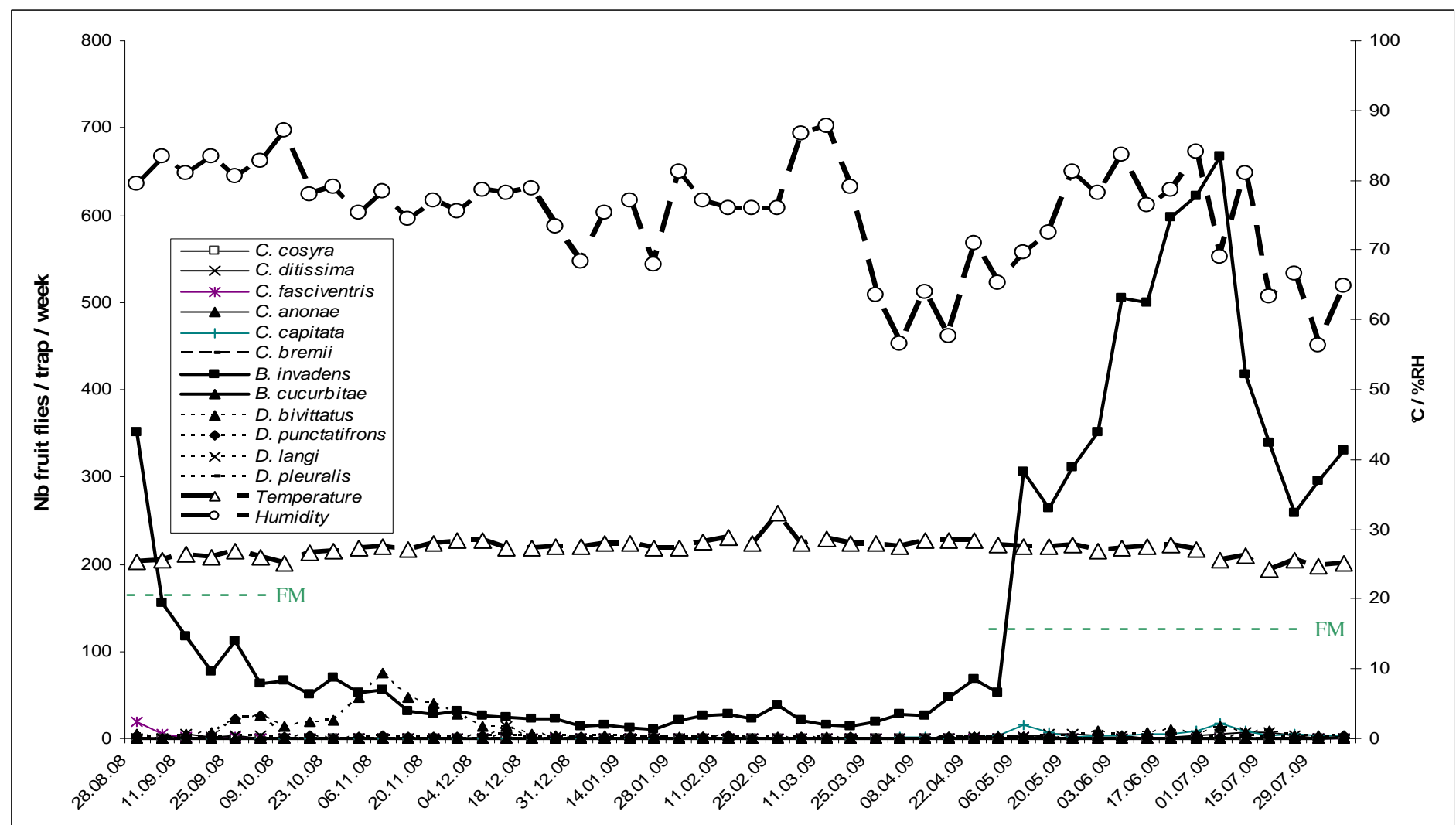

Figure 3: Amount of fruit flies (Ceratitis spp., Bactrocera spp., Dacus spp.) obtained per trap per week in relationship with temperature / relative humidity recorded in a citrus orchard in Lokodénou, Allada from August 2008 to August 2009. FM = fruiting - maturity. 
J. F. VAYSSIERES et al. / Int. J. Biol. Chem. Sci. 4(6): 1881-1897, 2010

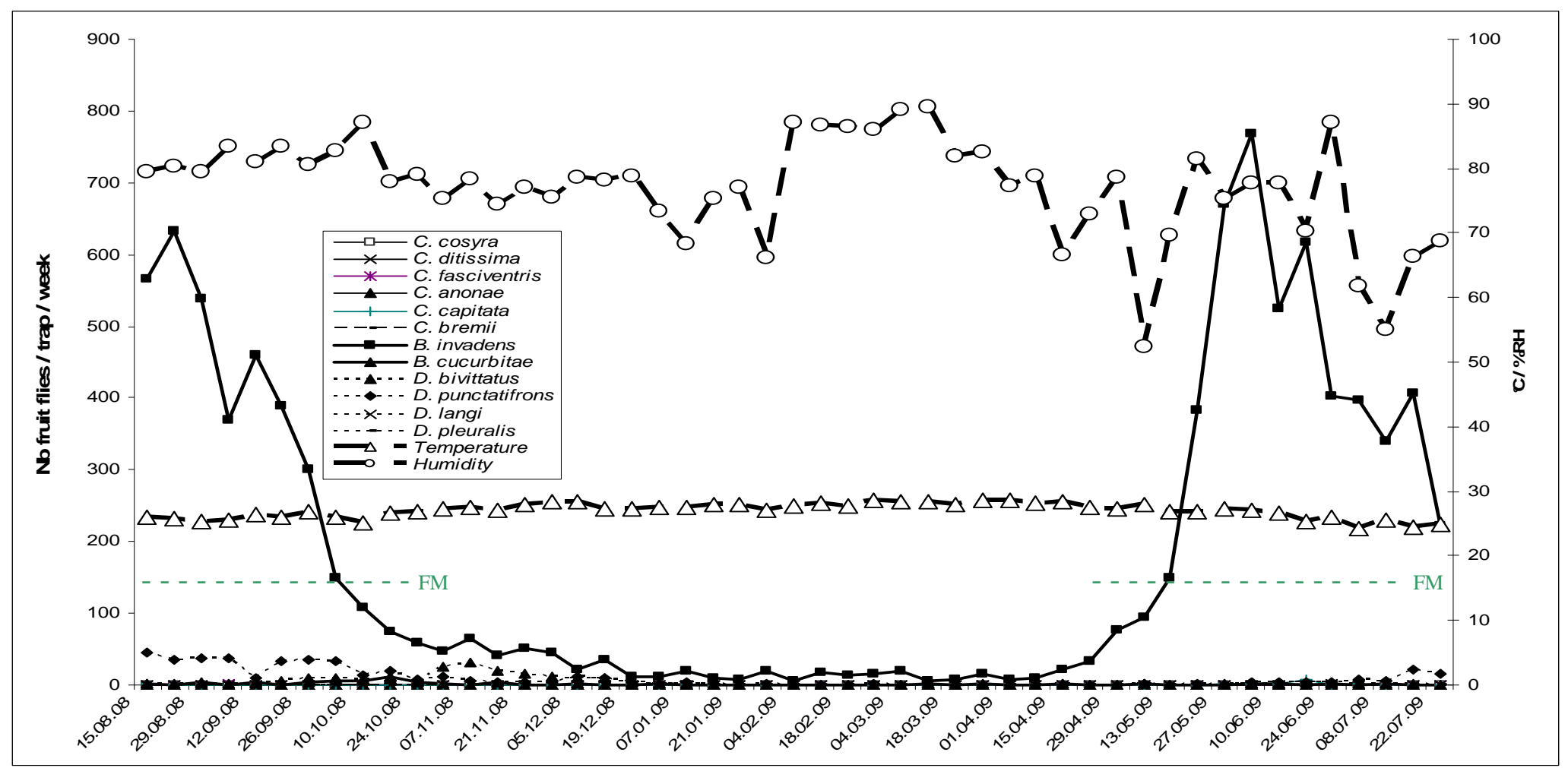

Figure 4: Amount of fruit flies (Ceratitis spp., Bactrocera spp., Dacus spp.) obtained per trap per week in relationship with temperature / relative humidity recorded in a citrus orchard in Sakété, from August 2008 to August 2009. FM = fruiting - maturity. 
Table 1: Presentation of the citrus orchards, their species and cultivars sampled in southern Benin in 2008-2009 with their ripening periods.

\begin{tabular}{|c|c|c|c|c|}
\hline $\begin{array}{l}\text { Location } \\
\text { and GPS coordinates }\end{array}$ & Orchard and surface & $\begin{array}{c}\% \text { Citrus } \\
\text { homogeneity }\end{array}$ & $\begin{array}{c}\text { Species and } \\
\text { cultivars }\end{array}$ & Ripening period \\
\hline \multirow{4}{*}{$\begin{array}{l}\text { Glo-djigbe, Abomey-Calavi, } \\
\text { N } 06^{\circ} 56^{\prime} 63^{\prime \prime} \\
\text { E 2 } 24^{\circ} 64^{\prime \prime}\end{array}$} & \multirow{4}{*}{ Citrus; 10 ha } & \multirow{4}{*}{$100 \%$} & $\begin{array}{l}\text { C. sinensis } \\
\text { (Valencia), } \\
\text { (Pineapple) }\end{array}$ & $\begin{array}{l}\text { From end June to end July } \\
\text { From end October to mi November }\end{array}$ \\
\hline & & & $\begin{array}{l}\text { C. tangelo } \\
\text { (Orlando), }\end{array}$ & $\begin{array}{l}\text { From end June to end July } \\
\text { From October to mi November }\end{array}$ \\
\hline & & & $\begin{array}{l}\text { C. reticulata } \\
\text { (Dancy), }\end{array}$ & $\begin{array}{l}\text { From beginning to end June } \\
\text { From mi October to beginning November }\end{array}$ \\
\hline & & & $\begin{array}{l}\text { C. } \text { sinensis } \times C \text {. } \\
\text { reticulata } \\
\text { (Ortanique) }\end{array}$ & $\begin{array}{l}\text { From mi July to end August } \\
\text { From beginning to end November }\end{array}$ \\
\hline $\begin{array}{l}\text { Govié, Allada } \\
\text { N } 06^{\circ} 67^{\prime} 16^{\prime}, \\
\text { E 2 }{ }^{\circ} 18^{\prime} 84^{\prime}, \\
\end{array}$ & Citrus; 3 ha & $100 \%$ & $\begin{array}{l}\text { C. sinensis }(\mathrm{cv} \\
\text { Valencia), }\end{array}$ & $\begin{array}{l}\text { From end June to end July } \\
\text { From end October to mi November }\end{array}$ \\
\hline $\begin{array}{l}\text { Lokodénou, Allada } \\
\text { N } 06^{\circ} 68^{\prime} 89^{\prime}, \\
\text { E } 2^{\circ} 20^{\prime} 30^{\prime}\end{array}$ & Citrus; 3 ha & $100 \%$ & $\begin{array}{l}\text { C. sinensis (cv } \\
\text { Valencia) } \\
\text { C. sinensis (cv } \\
\text { Pineapple) } \\
\end{array}$ & $\begin{array}{l}\text { From end June to end July } \\
\text { From end October to mi November } \\
\text { From mi July to beginning August } \\
\text { From beginning to end November }\end{array}$ \\
\hline \multirow{2}{*}{$\begin{array}{l}\text { Itadjèbou, Sakété } \\
\text { N } 06^{\circ} 81 \text { '57', } \\
\text { E 2 } 61^{\circ} 06^{\prime},\end{array}$} & \multirow[t]{2}{*}{ Citrus; 3 ha } & \multirow[t]{2}{*}{$100 \%$} & $\begin{array}{l}\text { C. sinensis } \\
\text { (Valencia), }\end{array}$ & $\begin{array}{l}\text { From end June to end July } \\
\text { From end October to mi November }\end{array}$ \\
\hline & & & $\begin{array}{l}\text { C. reticulata } \\
\text { (Dancy) }\end{array}$ & $\begin{array}{l}\text { From beginning to end June } \\
\text { From mi October to beginning November }\end{array}$ \\
\hline
\end{tabular}




\section{J. F. VAYSSIERES et al. / Int. J. Biol. Chem. Sci. 4(6): 1881-1897, 2010}

Table 2: Tephritidae trapped in citrus orchards within the four sampling sites in southern Benin, from August 2008 to August 2009.

\begin{tabular}{|c|c|c|c|c|c|c|c|c|c|c|}
\hline & \multicolumn{2}{|c|}{ Glo (Abomey-Calavi) } & \multicolumn{2}{|c|}{ Govié (Allada) } & \multirow{2}{*}{\multicolumn{2}{|c|}{$\begin{array}{r}\text { Lokodénou (Allada) } \\
\text { rate }(\%)\end{array}$}} & \multicolumn{2}{|c|}{ Sakété 2 (Sakété) } & \multicolumn{2}{|c|}{ Total captures } \\
\hline & & rate $(\%)$ & & rate $(\%)$ & & & & rate & Total & Rate \% \\
\hline & Amount & & Amount & & Amount & & Amount & $(\%)$ & amount & \\
\hline Ceratitis cosyra & 25 & 0.14 & 14 & 0.05 & 29 & 0.12 & 7 & 0.03 & 75 & 0.08 \\
\hline Ceratitis ditissima & 43 & 0.25 & 204 & 0.72 & 52 & 0.22 & 5 & 0.02 & 304 & 0.33 \\
\hline Ceratitis fasciventris & 45 & 0.26 & 116 & 0.41 & 11 & 0.05 & 4 & 0.02 & 176 & 0.19 \\
\hline Ceratitis anonae & 11 & 0.06 & 10 & 0.04 & 1 & 0.00 & 0 & 0.00 & 22 & 0.02 \\
\hline Ceratitis capitata & 363 & 2.08 & 338 & 1.19 & 155 & 0.66 & 50 & 0.21 & 906 & 0.97 \\
\hline Ceratitis bremii & 4 & 0.02 & 8 & 0.03 & 3 & 0.01 & 1 & 0.00 & 16 & 0.02 \\
\hline Bactrocera invadens & 14671 & 84.00 & 25890 & 91.15 & 20363 & 86.46 & 21583 & 91.58 & 82507 & 88.73 \\
\hline Bactrocera cucurbitae & 53 & 0.30 & 36 & 0.13 & 34 & 0.14 & 231 & 0.98 & 354 & 0.38 \\
\hline Dacus bivittatus & 1937 & 11.09 & 1523 & 5.36 & 2088 & 8.87 & 376 & 1.60 & 5924 & 6.37 \\
\hline Dacus punctatifrons & 303 & 1.73 & 255 & 0.90 & 808 & 3.43 & 1303 & 5.53 & 2669 & 2.87 \\
\hline Dacus langi & 5 & 0.03 & 6 & 0.02 & 3 & 0.01 & 6 & 0.03 & 20 & 0.02 \\
\hline Dacus pleuralis & 6 & 0.03 & 4 & 0.01 & 4 & 0.02 & 2 & 0.01 & 16 & 0.02 \\
\hline Total number of captures & 17466 & 100 & 28404 & 100 & 23551 & 100 & 23568 & 100 & 92989 & 100 \\
\hline
\end{tabular}

Table 3: Diversity indices of the Tephritid populations at the 4 different sites in southern Benin.

\begin{tabular}{|c|c|c|c|c|}
\hline Sites & Species richness* & Shannon index $\left(H^{\prime}\right)^{*}$ & Shannon evenness $\left(\mathbf{E}_{\mathbf{H}}\right)^{*}$ & Simpson index* \\
\hline Glo & $4.400 \pm 0.250$ & $0.500 \pm 0.050$ & $0.351 \pm 0.034$ & $0.735 \pm 0.030$ \\
\hline Allada 1 & $5.038 \pm 0.219$ & $0.452 \pm 0.035$ & $0.299 \pm 0.030$ & $0.771 \pm 0.023$ \\
\hline Allada 2 & $4.288 \pm 0.191$ & $0.544 \pm 0.046$ & $0.399 \pm 0.040$ & $0.702 \pm 0.030$ \\
\hline Sakété & $3.927 \pm 0.177$ & $0.440 \pm 0.043$ & $0.320 \pm 0.034$ & $0.771 \pm 0.025$ \\
\hline
\end{tabular}

$*$ Mean \pm SE. No significant difference was detected among means under the SAS program. 
Table 4: Percentage of fruit fly species emerging from Citrus spp. collected in southern Benin, mean number of pupae recorded per kg fruit and incidence.

\begin{tabular}{|c|c|c|c|c|c|c|c|c|c|c|c|c|c|c|c|c|}
\hline \multirow[b]{2}{*}{ Crops studied } & \multicolumn{2}{|c|}{ B. invadens } & \multicolumn{4}{|c|}{ B. cucurbitae $C$. fasciventris } & \multicolumn{2}{|c|}{ C. ditissima } & \multicolumn{2}{|c|}{ C. anonae } & \multicolumn{2}{|c|}{ D. bivittatus } & \multicolumn{2}{|c|}{$\begin{array}{l}\text { D. } \\
\text { punctatifrons }\end{array}$} & \multirow[t]{2}{*}{$\begin{array}{c}\text { Mean number of } \\
\text { pupae per kg } \\
\text { fruit* }\end{array}$} & \multirow[t]{2}{*}{$\begin{array}{c}\text { Incidence } \\
(\%)^{*}\end{array}$} \\
\hline & Total & $\%$ & Total & $\%$ & Total & $\%$ & Total & $\%$ & Total & $\%$ & Total & $\%$ & Total & $\%$ & & \\
\hline C. sinensis, cv. Valencia & 392 & 98.2 & 1 & 0.3 & 1 & 0.3 & 1 & 0.3 & - & - & 1 & 0.3 & 3 & 0.8 & $5.3 \pm 0.9 \mathrm{a}$ & $20.4 \pm 3.2 \mathrm{~b}$ \\
\hline C. sinensis cv. Pineapple & 50 & 100.0 & - & - & - & - & - & - & - & - & - & - & - & - & $1.7 \pm 1.1 \mathrm{a}$ & $8.6 \pm 1.8 \mathrm{a}$ \\
\hline C. reticulata & 360 & 98.5 & - & - & 1 & 0.3 & 1 & 0.3 & 1 & 0.3 & 1 & 0.3 & 1 & 0.3 & $22.5 \pm 2.6 b$ & $35.0 \pm 6.6 \mathrm{c}$ \\
\hline C. tangelo & 209 & 96.8 & - & - & 2 & 0.9 & 2 & 0.9 & 2 & 0.9 & 1 & 0.5 & - & - & $18.7 \pm 1.0 \mathrm{~b}$ & $27.1 \pm 10.1 \mathrm{bc}$ \\
\hline C. reticulata $\times$ C. sinensis & 20 & 100.0 & - & - & - & - & - & - & - & - & - & - & - & - & $2.9 \pm 1.0 \mathrm{a}$ & $10.0 \pm 6.7 \mathrm{a}$ \\
\hline
\end{tabular}

$*$ Mean \pm SE. In the same column, values followed by a different letter are significantly different $(p<0.05)$ according to Student Newman-Keuls test.

Table 5: Fruit fly species emerging from four other cultivated hosts and three local hosts collected in southern Benin, and mean number of pupae recorded per $\mathrm{kg}$ fruit.

\begin{tabular}{lcc}
\hline & Mean number* of pupae per kg fruit & Species emerged \\
\hline Carica papaya & $13.9 \pm 1.6 \mathrm{a}$ & B invadens, D. bivittatus \\
Psidium guajava & $21.4 \pm 1.5 \mathrm{a}$ & B. invadens, C. fasciventris \\
Annona muricata & $24.2 \pm 3.4 \mathrm{a}$ & B. invadens, C. cosyra \\
Mangifera indica & $36.0 \pm 7.9 \mathrm{~b}$. & B. invadens, C. fasciventris, C. cosyra \\
Chrysophyllum albidum & $37.7 \pm 6.3 \mathrm{~b}$ adens, C. fasciventris, C. ditissima \\
Irvingia gabonensis & $44.1 \pm 5.4 \mathrm{~b}$ & B. invadens \\
Terminalia catapa & $92.7 \pm 15.0 \mathrm{c}$ & B. invadens \\
\hline *Mean \pm SE. In the same column, values followed by a different letter are significantly different $(p<0.05)$ according to Student-Newman-Keuls test.
\end{tabular}


In southern Benin, the fruit fly detection-trapping results showed that $B$. invadens was the most predominant fruit fly recorded in the orchards. It was followed by D. bivittatus. Our sampling of papaya showed that papaya can host this species (Table 5) as $B$. invadens. Since the orchards of Glo, Lokdénou and Govié are edged by many papayas where fruits were picked up we know where D. bivittatus is mainly developing. We also found a few emergences of $D$. bivittatus in Borgou department in 2008 and 2009 from a few mangoes (Mangifera indica) and sweet oranges ( $C$. sinensis) (unpublished data).

For other species, some of the recorded Ceratitis species had already been reported in the mango orchards: $C$. cosyra in Mali (Noussourou and Diarra, 1995, Vayssières et al., 2007) and in Benin (Vayssières et al., 2009a), C. fasciventris and C. anonae in Benin (Vayssières et al., 2005). $C$. ditissima was seldom reported in Mangifera orchards in Mali (Vayssières et al., 2007) and in the current study, this species was recorded in Citrus orchards because $C$. ditissima is also hosted by various citrus fruits. We should also mention the presence of some moths, Thaumatotibia leucotreta Meyrick (Lepidoptera: Tortricidae), which very seldom emerged from some sweet oranges. After emergence of adults, the brown open cavity becomes a point of entry for other pests and pathogens.

\section{Lure responses}

Each parapheromone can attract several species of different genera eventually. All these lure responses were already reported. Methyl eugenol is a very potent attractant which is able to attract high numbers of $B$. invadens and sometimes a few adults of $C$. bremii. Cuelure is a parapheromone primarily effective for the melon fly, B. cucurbitae, but also for the genus Dacus. During the current trapping, it mostly captured males of $D$. bivittatus and D. punctatifrons already reported in Benin (White, 2006) and from most West African countries. It was surprising to note that $C$. capitata, attracted by Trimedlure, was not really abundant in these Beninese Citrus orchards.
Incidence and infestation rates of Tephritidae in Citrus fruits

From all fruits sampled, emerged fruit fly species were mostly B. invadens $(98.3 \%)$ and secondarily B. cucurbitae, C. fasciventris, $C$. ditissima, $C$. anonae, D. bivittatus and $D$. punctatifrons (Table 4). We did not have any reported emergence of $C$. capitata from citrus fruits. This is interesting because a few years ago this pest was very abundant on citrus fruits in central and southern Nigerian (Umeh et al., 2004) citrus orchards as well as in central and southern Ghanaian citrus orchards in 2006 (Fappiah et al., 2009). However, $C$. capitata is still the main fly pest in those areas of citrus production where $B$. invadens is not present, i.e. in South Africa (Barnes et al., 2007), in South America in Argentina (Segura et al., 2006), in Europe in Greece (Papachristos et al., 2008) and Israel (Israely et al., 2005).

The infestation rates in Benin are roughly equal to those in Kenya (Rwomushana et al., 2008) and Tanzania (Mwatawala et al,. 2009) for B. invadens in sweet orange. But infestation rates in Benin are higher than in Kenya (Rwomushana et al., 2008) and Tanzania (Mwatawala et al., 2009) for $B$. invadens in tangelo and mandarin. Among the citrus species studied in the current work, $C$. reticulata seems to be more susceptible, followed by $C$. tangelo and $C$. sinensis. It was observed that the infestation rate was highest as the fruit matured and no or little infestation was recorded at pre-maturity stages of the sampled fruits, corroborating the work of Dominiak (2008), who indicated that citrus fruit is increasingly likely to be attacked as it becomes more mature and as the fruit fly population increases. Consequently, some fruits, such as most citrus varieties early in their seasons, are not generally suitable for larval development even though the flies lay eggs in these fruits. Moreover, Dominiak (2008) reported that larvae develop more successfully in fruits such as $C$. reticulata, grapefruit, Meyer lemons, $C$. tangelo and $C$. sinensis $\times C$. reticulata than in oranges because larvae in these fruits, often feed in the thick skin and central pith rather than the juice cells. 
The main fruit fly species emerging from sampled fruits collected from other cultivated or wild plants was B. invadens. These fly populations on other fruit crops may constitute an initial reservoir that subsequently affects the fluctuations in fruit fly populations colonizing citrus trees in southern Benin. These fruit crops, especially wild species, contribute to the multiplication of the species, since they are alternative hosts to the citrus trees. Consequently, these trees represent the fruit fly reservoir that will attack the cultivated trees at susceptible stages. Of particular note is the emergence of fruit flies from $T$. catappa, or tropical almond, which showed the highest infestation rate, about four-fold higher than that from cultivated fruit trees sampled, recorded in the current study. T. catappa was also found to be the most infested uncultivated plant in Kenya (Rwomushana et al., 2008) and in Tanzania (Mwatawala et al., 2009). This wild plant evidently ensures that sufficient reproductive bases exist for $B$. invadens and other fruit flies during the off-season when the cultivated hosts are not in fruiting. It is known that fruits of cultivated crops other than mango and citrus and wild host plants also harbor larvae of Tephritidae all year round as reservoir hosts (Vayssières et al., 2005; Mwatawala et al., 2006; Rwomushana et al., 2008). Such cultivated and wild fruit plant hosts are often found near orchards. It is important to include these alternative fruit plant hosts in any control program to ensure the effectiveness of the control measures targeting these fruit fly pests in the orchards.

The very weak abundance of $C$. capitata, $C$. fasciventris and $C$. anonae number could be the result of the introduction and the dispersal of the new invasive species $B$. invadens. As we have observed for mango fruit fly species such as C. cosyra (Vayssières et al., 2005), this exotic species is outperforming and displacing indigenous fly species. We have several examples of polyphagous invasive species with high biotic potentialities displacing indigenous species. Most recent articles focused on displacement of $C$. capitata by B. zonata on Reunion Island (Duyck et al., 2004; 2008), C. capitata by $B$. dorsalis in the Hawaiian Islands (Reitz and
Trumble, 2002), and C. cosyra by B. invadens in Kenya (Ekesi et al., 2009; Mwatawala et al., 2009). Its competitive displacement by $B$. invadens could be the reason for the absence of $C$. capitata from sampled fruits, as suggested above.

\section{Conclusion}

This is the first report of a study on fruit fly population fluctuations in citrus orchards which are a source of essential dietary components (vitamins, minerals). The results of the current study are of paramount importance since they show the extent to which fruit flies, especially B. invadens, occur and infest southern Benin citrus crops. The occurrence of fruit flies in this part of the country shows that the exotic species, $B$. invadens, represents a major threat to Citrus crops in southern Benin. The recorded infestation rate and incidence on citrus fruits during this work from August 2008 to August 2009 were more than $20 \%$ and $35 \%$, respectively, depending on the citrus species. However, it shows the potential losses in growers' incomes and yield, and highlights how necessary it is to develop control strategies against fruit flies. In this way, it would be urgent to test spinosad bait-sprays in these Citrus orchards in order to know if they will give as good results as in mango orchards (Vayssières et al., 2009b) in central and northern Benin.

\section{ACKNOWLEDGMENTS}

We would like to extend our thanks to growers for their encouragements during the study carried out in their orchards. This study was funded by WB, UE, WTO, IITA and CIRAD. We are extremely grateful for all their confidence in our work. We also thank most sincerely David Millar and two anonymous reviewers who made a number of relevant remarks.

\section{REFERENCES}

Alemany A, Miranda MA, Alonso R, Escorza CM. 2006. Changes in the spatial and temporal population density of the Mediterranean fruit fly (Diptera: Tephritidae) in a citrus orchard. Spanish 
Journal of Agricultural Research, 4: 161166.

Barnes B, Rosenberg S, Arnolds L, Johnson J. 2007. Production and quality assurance in the SIT Africa: Mediterranean fruit fly (Diptera: Tephritidae) rearing facility in South Africa. Florida Entomologist, 90: 41-52.

Dalirsefat S, Meyer A, Mirhoseini S. 2009. Comparison of similarity coefficients used for cluster analysis with amplified fragment length polymorphism markers in the silkworm, Bombyx mori. Journal of Insect Science, 9:1-8.

Da Silva FF, Meirelles RN, Redaelli LR, Dal Soglio FK 2006. Diversity of flies (Diptera: Tephritidae and Lonchaeidae) in organic citrus orchards in the Vale do Rio Cai, Rio Grande do Sul, Southern Brazil. Neotropical Entomology, 35: 666-670.

Dominiak B. 2008. Queensland fruit fly. Primefact 520, pp 1-4. www.dpi.nsw.gov.au

Duyck P-F, David P, Quilici S. 2004. A review of relationships between interspecific competition and invasions in fruit flies (Diptera Tephritidae). Ecological Entomology, 29: 511-520.

Duyck P-F, David P, Pavoine S, Quilici S. 2008. Can host-range allow niche differentiation of invasive fruit flies (Diptera: Tephritidae) in La Réunion? Ecological Entomology, 33: 439-452.

Du Toit WJ. 1998. Fruit flies. In Citrus Pests in the Republic of South Africa $\left(2^{\text {nd }}\right.$ edn revised), Bedford, Van Den Berg, De Villiers (eds). Institute for Tropical and Subtropical Crops: Nelspruit; 229-233.

Ekesi S, Billah M, N'deritu PW, Lux SA, Rwomushana I. 2009. Evidence for Competitive Displacement of Ceratitis cosyra by the Invasive Fruit Fly Bactrocera invadens (Diptera: Tephritidae) on Mango and Mechanisms Contributing to the Displacement. $J$. Econ. Entomol., 102: 981-991.

Fappiah F, Kwame Afreh-Nuamah, ObengOfori. 2009. Abundance and distribution of the Mediterranean fruit fly Ceratitis capitata (Diptera: Tephritidae), in late Valencia citrus orchards in Ghana.
International Journal of Tropical Insect Science, 29: 11-16.

Grout TG, Stoltz KC. 2007. Developmental rates at constant temperatures of three economically important Ceratitis spp. (Diptera: Tephritidae) from Southern Africa. Environmental Entomology, 36: 1310-1317.

Israely N, Ziv Y, Oman SD. 2005. Spatiotemporal distribution patterns of Mediterranean fruit fly (Diptera Tephritidae) in the central region of Israel. Ann. Entomol. Soc., 98: 77-84.

Kosman E, Leonard KJ. 2005. Similarity coefficients for molecular markers in studies of genetic relationships between individuals for haploid, diploid and polyploid species. Molecular Ecology, 14: 415-424.

Llod AC, Hamacek EL, Kopittke RA, Peek T, Wyatt PM, Neale CJ, Elkema M. 2010. Area-wide management of fruit flies (Diptera: Tephritidae) in the Central Burnett district of Queensland, Australia. Crop Protection, 29: 462-469.

Lux SA, Ekesi S, Dimbi S, Mohamed S, Billah M. 2003. Mango-infesting fruit flies in Africa: perspectives and limitations of biological approaches to their management. In Biological control in IPM systems in Africa, Neuenschwander P, Borgemeister C, Langewald J. (eds). CAB Int.: Wallingford, UK ; 277-298.

Mwatawala MW, De Meyer M, Makundi RH, Maerere AP. 2006 Seasonality and host utilization of the invasive fruit fly, Bactrocera invadens (Diptera, Tephritidae) in central Tanzania. Journal of Applied Entomology, 130: 530-537.

Mwatawala MW, De Meyer M, Makundi RH, Maerere AP. 2009. Host range and distribution of fruit-infesting pestiferous fruit flies (Diptera, Tephritidae) in selected areas of Central Tanzania. Bulletin of Entomological Research, (doi:10.1017/S0007485309006695).

Noussourou M, Diarra B. 1995. Lutte intégrée contre les mouches des fruits. Sahel IPM, 6 : 2-13.

Oates RK, Pavuk DM, Purrington FF, With KA, Bergolc ML, Hite-Bechstein K, 
Hughes-Williams L. 2005. Carabid beetle (Coleoptera: Carabidae) diversity in forest fragments of northwestern Ohio. American Entomologist, 51: 237-239.

Papachristos D, Papadopoulos N, Nanos GD. 2008. Survival and development of immature stages of the Mediterranean fruit fly (Diptera: Tephritidae) in Citrus fruit. J. Econ. Entomol., 101: 866-872.

Quilici S, Thuy Nguyen N. 2004. Response of female Medfly, Ceratitis capitata (Diptera: Tephritidae), to olphactory stimuli from various plants in a wind tunnel. Proceeding of the $6^{\text {th }}$ International Symposium on fruit flies of economic importance, Stellenbosch, South Africa, 6-10 May 2002.

Reitz SR, Trumble JT. 2002. Competitive displacement among insects and arachnids. Annual Review of Entomology, 47: 435-465.

Rwomushana I, Ekesi S, Gordon I, Ogol CKPO. 2008. Host plants and host plant preference studies for Bactrocera invadens (Diptera: Tephritidae) in Kenya, a new invasive fruit fly species in Africa. Annals of the Entomological Society of America, 101: 331-340.

Sanjeev R, Uma S, Bhagat RM, Gupta SP. 2008. Population dynamics and succession of fruit fly on sub-tropical fruits under rainfed condition in Jammu Region. Indian Journal of Entomology, 70: $12-15$.

SAS 2003. The SAS System for Windows, version 9.1 computer program. Cary, NC: SAS.

Segura DF, Vera MT, Cagnotti CL, Vaccaro N, De Coll O, Ovruski SM, Cladera JL. 2006. Relative abundance of Ceratitis capitata and Anastrepha fraterculus (Diptera: Tephritidae) in diverse host species and localities of Argentina. Ann. Entomol. Soc. Am., 99: 70-83.

Thompson F.C. 1998. Fruit fly expert identification system and systematic information database. Myia, 9: 1-224.
Umeh VC, Olaniyan AA, Ker J, Andir J. 2004. Development of citrus fruit fly control strategies for small holders in Nigeria. Fruits, 59: 265-274.

Umeh VC, Garcia EL, De Meyer M. 2008. Fruit flies of Citrus in Nigeria: species diversity, relative abundance and spread in major producing areas. Fruits, 63: 145153.

Vayssières J-F, Georgen G, Lokossou O, Dossa P, Akponon C. 2005. A new Bactrocera species in Benin among mango fruit fly (Diptera: tephritidae) species. Fruits, 60: 371-377.

Vayssières J-F, Korie S, Ayegnon D. 2009a. Correlation of fruit fly (Diptera Tephritidae) infestation of major mango cultivars in Borgou (Benin) with abiotic and biotic factors and assessment of damage. Crop Protection, 28: 477-488.

Vayssières J-F, Sinzogan A, Korie S, Ouagousounon I, Tomas-Odjo A. 2009b. Effectiveness of Spinosad Bait Sprays (GF-120) in controlling mango-infesting fruit flies (Diptera: Tephritidae) in Benin. J. Econ. Entomol., 102: 515-521.

Vayssières J-F, Sanogo F, Noussourou M. 2007. Inventory of the fruit fly species (Diptera: Tephritidae) linked to the mango tree in Mali and tests of integrated control. Fruits, 62: 329-341.

Vincenot D, Quilici S. 1993. Ile de la Réunion. Développement de la lutte intégrée en vergers d'agrumes. Phytoma, 456: 43-46.

White IE, Elson-Harris MM. 1992. Fruit Flies of Economic Significance: their Identification and Bionomics. CAB International: Wallingford, UK.

White IE. 2006. Taxonomy of the Dacina (Diptera: Tephritidae) of Africa and the Middle East. African Entomology, 2: 1156.

Yang Z, Cai P, Wang L. 2009. The occurrence and damage to the fruit trees of citrus small fruit fly in Sizhou area, Jiangsu province. South China Fruits, 2: 38-39. 